\title{
TRENDS IN TOBACCO SMOKING AMONG CZECH SCHOOL-AGED CHILDREN FROM 1994 TO 2014
}

\author{
Ferdinand Salonna ${ }^{1}$, Ladislav Kážmér ${ }^{2,3}$, Ladislav Csémy $^{2}$, Jana Vašíčková1, Anne Hublet ${ }^{4}$, Christiane Stock $^{5}$ \\ ${ }^{1}$ Faculty of Physical Culture, Palacký University Olomouc, Olomouc, Czech Republic \\ ${ }^{2}$ Centre of Epidemiological and Clinical Research of Drug Abuse and Dependence, National Institute of Mental Health, Klecany, Czech Republic \\ ${ }^{3}$ Department of Social Geography and Regional Development, Faculty of Sciences, Charles University, Prague, Czech Republic \\ ${ }^{4}$ Unit Health Promotion, Department of Public Health, Ghent University, Ghent, Belgium \\ ${ }^{5}$ Institute of Public Health, University of Southern Denmark, Esbjerg, Denmark
}

\section{SUMMARY}

Objective: The aim of the article is to examine trends in tobacco consumption among the Czech school-age population.

Methods: For the analysis, data from the Czech Health Behaviour in School-aged Children project, conducted between 1994 and 2014 were used. Trends in tobacco smoking were determined separately for boys and girls, applying the binary logistic regression with survey period as an independent variable for the smoking status.

Results: The analysis showed that there have been significant changes in adolescent tobacco smoking for the recent 20 years. While the share of current school-aged smokers was continuously increasing since the mid-1990s, the trend reached its peak in the mid-2000s.

Conclusion: In recent years, the prevalence of adolescent smokers has significantly declined in the Czech Republic. Despite this recent decline, adolescent smoking remains a major challenge for the national health policy.

Key words: tobacco smoking, adolescents, prevalence, trends

Address for correspondence: F. Salonna, Faculty of Physical Culture, Palacký University Olomouc, trída Míru 111, 77111 Olomouc, Czech Republic. E-mail: ferdinand.salonna@upol.cz

https://doi.org/10.21101/cejph.a5100

\section{INTRODUCTION}

Despite many reports on the negative health consequences of smoking, tobacco consumption is still the leading cause of preventable death in developed countries $(1,2)$. It has been estimated that the life expectancy for smokers is about 10 years shorter than for non-smokers (3). In a similar vein, it has been recognized that smoking increases the risk of a variety of diseases causing the major proportion of total deaths, including several sites of cancer, vascular diseases and chronic pulmonary diseases (4). In the Czech Republic, tobacco smoking is currently related to approximately $16 \%$ of total adult mortality $(23.5 \%$ in men and $10 \%$ in women) (5). The negative effects on health are proportional to the smoking exposure in terms of both number of years and frequency of tobacco consumption during the lifespan. Given the high burden of smoking-related harms and its direct effects on population morbidity and mortality, it is of major concern of public health in many developed countries all over the world.

Adolescence is a critical period for the future smoking habits in adulthood. Most of adult daily smokers tried their first cigarette before the age of 18 (6). However, once the habit changes to addiction, smoking is extremely difficult to break. It has been shown that less than half of all smokers successfully quit before the age of 60 (7).

Despite of all the negative health consequences, adolescents still may see positive aspects in smoking. The most prevalent func- tions of smoking are: controlling negative moods and depression (relaxation, concentration, stress reduction, boredom elimination); social group affiliation (smoking as a tool for joining a desired friendship group, for establishing contact with other gender); weight control (especially among girls); identification with a certain image of adulthood and self-reliance (8). More recent research reveals complexity of social roles that smoking plays in the life of adolescents $(9,10)$.

The research on prevalence of smoking among adolescent population provides important data for both the complex national monitoring of health-related behaviours and addressing the specific needs for national health policy. The information on recent trends can subsequently serve as an empirical evidence on changing behaviour of the growing-up part of the population, as a response to policy changes and preventative measures introduced in the past. The aim of this study is, therefore, the examination of trends in tobacco consumption in the Czech teenage population, covering relatively long period of 20 years. The paper refers to some other similar studies published in the past $(11,12)$.

\section{MATERIAL AND METHODS}

For the study, data from the series of nationally representative surveys on adolescents' health conditions were used; drawn from 
the Czech part of the international project of Health Behaviour in School-aged Children (HBSC). HBSC is a major cross-sectional study that deals with monitoring of young people's health, life satisfaction and its determinants. In the Czech Republic, HBSC has been conducted at four-year intervals since 1994. The project is based on a unified methodology, where all countries follow the same research protocol in terms of sampling, questionnaire and survey administration. A detailed description of the aims, methods and design of the study is available elsewhere (13). For this paper, data from the last 6 survey waves, conducted in the Czech Republic from 1994 to 2014, were used.

Regarding the analysis, data on the current status of adolescents' smoking were applied. The data were collected by self-administered questionnaire completed in the classroom in a standardized way. Among the other HBSC questions on adolescent tobacco consumption, data on the current smoking status were the only ones that were fully comparable to the other waves of the survey.

The question used in the analysis was as follows: "How often do you smoke tobacco at present?" The possible answers were: 'every day'; 'at least once a week, but not every day'; 'less than once a week'; 'I do not smoke'. Respondents 11, 13 and 15 years old were asked this question. Those who answered 'I do not smoke' were then coded as non-smokers; other responses were coded as current adolescent smokers.

The analysis was carried out in two steps. In the first step, agespecific prevalence estimates of adolescent current smoking with corresponding $95 \%$ confidence intervals $(95 \% \mathrm{CI})$ were computed for the three age groups (11-, 13- and 15-year olds) and plotted to graph. Trends in smoking were assessed both visually and by fitted trend curve. The shape of the curve was determined by consecutive fitting of linear, logarithmic, exponential, and polynomial trends. The shape with the highest fit $\left(\mathrm{R}^{2}\right)$ was selected - in our case, the quadratic trend.

In the second step of the analysis, trends in adolescent current smoking were tested by binary logistic regression. Based on the previous results, following regression equation was estimated:

$\log [\pi /(1-\pi)]=$ Constant $+\beta_{1} \cdot($ period $)+\beta_{2} \cdot\left(\right.$ period $\left.^{2}\right)$, period $=0,4,8,12,16,20$; where $\pi$ is the prevalence of adolescent current smokers and period is a number of years since the first HBSC survey in 1994. Lastly, the peak of the quadratic trend (vertex) was computed from the estimated regression coefficients.

The analysis was conducted both separately by gender and for total student population. As the prevalence of current smokers was very low among the 11-year olds, trend analyses were tested only among 13- and 15-year old students.

\section{RESULTS}

Table 1 presents description of the sample used in our study. Number of respondents surveyed in each cross-sectional period is presented separately by their gender and age. The sample size varied from 3,585 students in 1994 to 5,055 in 2014 with a proportional share of 11-, 13- and 15-year olds in each wave (approximately one third of the respondents per age group). The total sample size, compiled from all 6 survey periods, was 26,589 (a total of 13,021 boys and 13,568 girls).

In Table 2, age-specific prevalence estimates of adolescent current smoking are presented in the 20 -year time series since 1994. The proportion of smoking adolescents gradually increases with students' age. For example, in 2002, there was almost 30\% of current smokers among 15-year old Czechs, while it was 11\% among 13 -year olds and only $2 \%$ among 11 -year olds. Regarding differences between genders, these were apparent only at the beginning of the analysed period, with higher rates of smoking among boys. During the 2000s, gender differences declined and, in recent years, higher prevalence estimates were even observed among girls.

Trends in adolescent smoking are plotted in Fig1abc, separately by age-group and gender. The corresponding 95\% CIs of prevalence estimates are also presented. As one may observe, there were significant changes in adolescent smoking since the mid-1990s, particularly among 13- and 15-year olds. While there was a strong increase in the share of smoking teenagers between 1994 and 2002, the trend was rather declining in 2006 and 2010.

Table 1. Sample structure for the study by gender, age and the year of survey, Czech Republic, HBSC data 1994-2014

\begin{tabular}{|c|c|c|c|c|c|c|c|}
\hline \multirow{2}{*}{ Gender } & \multirow{2}{*}{ Age group } & \multicolumn{6}{|c|}{ Year of survey } \\
\hline & & 1994 & 1998 & 2002 & 2006 & 2010 & 2014 \\
\hline \multirow{4}{*}{ Boys } & 11 years old & 539 & 586 & 826 & 765 & 719 & 738 \\
\hline & 13 years old & 644 & 646 & 780 & 804 & 669 & 818 \\
\hline & 15 years old & 606 & 607 & 806 & 842 & 747 & 852 \\
\hline & Total boys & 1,789 & 1,839 & 2,412 & 2,411 & 2,135 & 2,408 \\
\hline \multirow{4}{*}{ Girls } & 11 years old & 555 & 598 & 865 & 744 & 707 & 836 \\
\hline & 13 years old & 646 & 644 & 881 & 797 & 787 & 903 \\
\hline & 15 years old & 595 & 622 & 854 & 823 & 775 & 908 \\
\hline & Total girls & 1,796 & 1,864 & 2,600 & 2,364 & 2,269 & 2,647 \\
\hline \multirow{4}{*}{ Total } & 11 years old & 1,094 & 1,184 & 1,691 & 1,509 & 1,426 & 1,574 \\
\hline & 13 years old & 1,290 & 1,290 & 1,661 & 1,601 & 1,456 & 1,721 \\
\hline & 15 years old & 1,201 & 1,229 & 1,660 & 1,665 & 1,522 & 1,760 \\
\hline & Total sample size & 3,585 & 3,703 & 5,012 & 4,775 & 4,404 & 5,055 \\
\hline
\end{tabular}


Table 2. Current smoking prevalence estimates (\%), by gender, age and the year of survey, Czech Republic, HBSC 1994-2014

\begin{tabular}{|c|c|c|c|c|c|c|c|}
\hline \multirow{2}{*}{ Gender } & \multirow{2}{*}{ Age group } & \multicolumn{6}{|c|}{ Year of survey } \\
\hline & & 1994 & 1998 & 2002 & 2006 & 2010 & 2014 \\
\hline \multirow{3}{*}{ Boys } & 11 years old & 2.2 & 1.9 & 3.0 & 1.6 & 2.4 & 1.6 \\
\hline & 13 years old & 7.3 & 10.1 & 13.7 & 7.9 & 8.9 & 4.0 \\
\hline & 15 years old & 15.8 & 22.4 & 28.7 & 19.7 & 22.0 & 10.8 \\
\hline \multirow{3}{*}{ Girls } & 11 years old & 1.4 & 1.0 & 1.0 & 1.1 & 0.9 & 0.8 \\
\hline & 13 years old & 4.2 & 7.0 & 8.6 & 8.8 & 10.3 & 3.6 \\
\hline & 15 years old & 11.9 & 17.5 & 30.6 & 23.4 & 27.8 & 15.6 \\
\hline \multirow{3}{*}{ Total } & 11 years old & 1.8 & 1.4 & 2.0 & 1.3 & 1.6 & 1.2 \\
\hline & 13 years old & 5.7 & 8.5 & 11.0 & 8.3 & 9.7 & 3.7 \\
\hline & 15 years old & 13.9 & 19.9 & 29.7 & 21.6 & 25.0 & 13.3 \\
\hline
\end{tabular}

The most significant decline was, however, observed in the recent period of 2014.

In the last step of the analysis, trends in adolescent tobacco smoking were modelled by binary logistic regression. The analysis was conducted for 13- and 15-year old students, with the results presented in Table 3.

Regression analyses in Table 3 confirmed previous findings from Fig. $1 \mathrm{bc}$. The prevalence of adolescent smoking experienced significant non-linear changes in the Czech Republic since 1994. While the share of current school-age smokers was increasing since the mid-1990s, the trend reached its peak in the mid-2000s
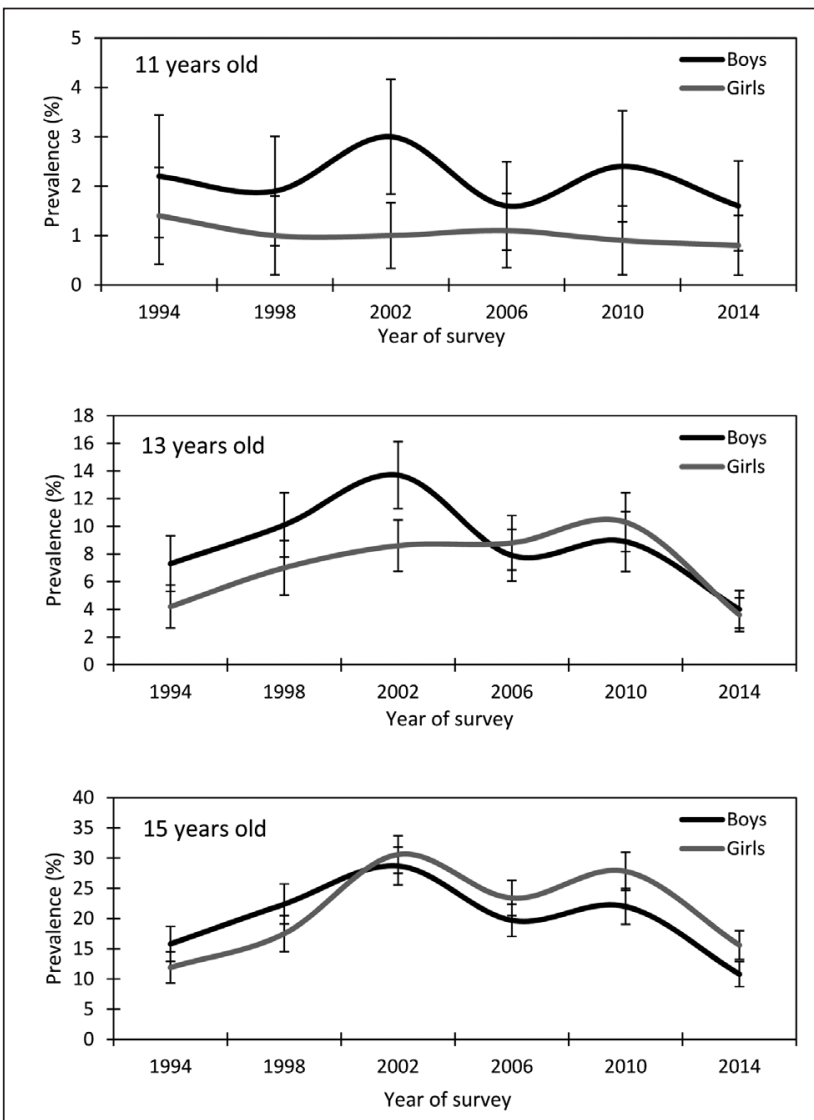

Fig. 1abc. Trends in current smoking (\%, 95\% Cl), by age and gender, Czech Republic, HBSC (1994-2014). and dropped in recent period (negative values of $\beta_{2}$ coefficients for period squared reflect the concave shape of the trend curve). Trends in tobacco smoking were similar in both genders, with approximately 2.5-year later onset of decline among girls (compared vertex estimates between the genders).

\section{DISCUSSION}

The results of our analysis prove the significant changes in the prevalence of tobacco smoking among the Czech adolescent population during the last 20 years. While the share of current school-age smokers was continuously increasing since the mid1990 s, the trend reached its peak in mid-2000s. In recent years, the prevalence of adolescent smoking has significantly decreased in the Czech Republic.

Our findings are in line with the results from other studies on trends in adolescent health-related behaviours conducted in Europe. Although the adolescent smoking is still of a concern for national health policies, data from the recent HBSC surveys indicate that the prevalence of smoking is declining in other European countries as well $(13,14)$.

The decline in smoking prevalence has been evident in Northern and Western European countries since 1998. The trend was, in general, similar in countries of the Southern Europe, with a slight increase in prevalence between 2006 and 2010. However, smoking among adolescents from the post-communist countries of Central Europe was and still is more common compared to their Western European peers. Based on our data from the HBSC study conducted in the Czech Republic, an increasing trend between years 1998 to 2002 was reported, followed by a slight continual increase to 2010. The decrease from 2010 to 2014 was the most impressive up to now.

The results of the ESPAD study are in line with the findings of the HBSC study. The last data collection from 2015 confirmed the overall decline in smoking in most of the countries. On average, about one in five (21\%) of European adolescents reported current smoking (during the past 30 days), as compared to $29 \%$ in the study carried out in 2011. In a similar vein, more European students reported they had never smoked (54\% in 2015; $44 \%$ in 2011). Between 2011 and 2015, the Czech students surveyed in ESPAD reported similar rapid decrease in smoking, as that re- 
Table 3. Binary logistic regression by gender and age. Dependent var. - Current smoking $(Y e s=1 ;$ No $=0)$, Czech Republic, HBSC 1994-2014

\begin{tabular}{|c|c|c|c|c|c|c|c|}
\hline \multirow{2}{*}{ Gender } & \multirow{2}{*}{ Age group } & \multirow{2}{*}{ Independenta) } & \multirow{2}{*}{ Beta (SE) } & \multicolumn{2}{|c|}{$95 \% \mathrm{Cl}$ for Beta } & \multirow{2}{*}{$p$ value } & \multirow{2}{*}{$\begin{array}{c}\text { Vertex } \\
\text { estimate }^{\text {b) }}\end{array}$} \\
\hline & & & & Lower & Upper & & \\
\hline \multirow{6}{*}{ Boys } & \multirow{3}{*}{13 years old } & Time period squared & $-0.008(0.001)$ & -0.011 & -0.005 & $<0.001$ & \multirow{3}{*}{7.9} \\
\hline & & Time period & $0.122(0.030)$ & 0.064 & 0.181 & $<0.001$ & \\
\hline & & Constant & $-2.514(0.132)$ & -2.773 & -2.255 & $<0.001$ & \\
\hline & \multirow{3}{*}{15 years old } & Time period squared & $-0.008(0.001)$ & -0.010 & -0.006 & $<0.001$ & \multirow{3}{*}{8.7} \\
\hline & & Time period & $0.136(0.021)$ & 0.095 & 0.177 & $<0.001$ & \\
\hline & & Constant & $-1.645(0.097)$ & -1.835 & -1.455 & $<0.001$ & \\
\hline \multirow{6}{*}{ Girls } & \multirow{3}{*}{13 years old } & Time period squared & $-0.009(0.002)$ & -0.012 & -0.006 & $<0.001$ & \multirow{3}{*}{10.5} \\
\hline & & Time period & $0.194(0.035)$ & 0.125 & 0.263 & $<0.001$ & \\
\hline & & Constant & $-3.229(0.173)$ & -3.568 & -2.891 & $<0.001$ & \\
\hline & \multirow{3}{*}{15 years old } & Time period squared & $-0.009(0.001)$ & -0.011 & -0.007 & $<0.001$ & \multirow{3}{*}{11.2} \\
\hline & & Time period & $0.203(0.022)$ & 0.160 & 0.246 & $<0.001$ & \\
\hline & & Constant & $-2.053(0.109)$ & -2.267 & -1.840 & $<0.001$ & \\
\hline \multirow{6}{*}{ Total } & \multirow{3}{*}{13 years old } & Time period squared & $-0.008(0.001)$ & -0.010 & -0.006 & $<0.001$ & \multirow{3}{*}{9.2} \\
\hline & & Time period & $0.150(0.022)$ & 0.106 & 0.194 & $<0.001$ & \\
\hline & & Constant & $-2.820(0.105)$ & -3.026 & -2.615 & $<0.001$ & \\
\hline & \multirow{3}{*}{15 years old } & Time period squared & $-0.008(0.001)$ & -0.010 & -0.007 & $<0.001$ & \multirow{3}{*}{10.1} \\
\hline & & Time period & $0.166(0.015)$ & 0.137 & 0.196 & $<0.001$ & \\
\hline & & Constant & $-1.834(0.072)$ & -1.976 & -1.693 & $<0.001$ & \\
\hline
\end{tabular}

a) Time period is a continuous variable representing number of years since the baseline period 1994 .

b)Vertex represents the time period, where the estimated quadratic regression function reaches its maximum.

ported in the HBSC study. Despite this decrease, the prevalence of smoking among young Czechs is still higher than the European average or the smoking in Scandinavia and in most of the Western European countries. $(13,15,17,20)$.

According to our findings, differences in the smoking prevalence between genders were apparent only at the beginning of the analysed period, with higher rates of smoking among boys. The gender differences declined during the 2000s, and, in recent years, there have been even higher rates of smoking among girls. The phenomenon of decline of gender inequalities in smoking is not unique for the Czech students only. It has been documented by international studies based on data from the HBSC in Europe (14), as well as in a global perspective on the data from the Global Youth Tobacco Survey $(15,16)$.

As regards the decline in both prevalence and gender inequalities in adolescent smoking, the descriptive model of cigarette epidemic proposed by Lopez et al. (21) states there are four main stages of tobacco consumption that can be recognized in developed countries. The stages are characterized by distinctive patterns of both prevalence of smoking and smoking-attributable mortality in the population, differentiated between the genders (the onset of the smoking epidemic among women is delayed to that among men). In its final stages, prevalence of smoking continually declines among both genders, possibly with higher prevalence rates among women (depending on the specific stage). Although the model was proposed for adult population, some parallels with the research aimed at adolescents is apparent. The model is, however, descriptive and do not refer to broader social factors related to the smoking behaviour, other than income, availability of tobacco products and preventative policy measures. Therefore, concerning particularly inequalities between genders, factors of converging gender-specific social roles, perceived norms and expectations in the society should be emphasized as well (22).

Given the method used in our study, we also point to some potential limitations related to the findings presented in the paper. In the analysis, we used self-reported information on adolescent substance use, collected within the large school-based survey. Although self-reports are, in general, considered as a good estimator of the smoking status (23), factors related to possible underreporting of the actual prevalence among the adolescent population should be still taken into account (24). In the school-based study, such bias may arise in situations, where a specific group of students is not included in the survey, e.g. due to school dropouts or absenteeism. Similarly, specific recall bias on the actual frequency of substance use and/or perceived normativity on adolescent behaviour may play a certain role, too. Furthermore, the presented study is rather descriptive and cannot provide evidence on causes underlying the recent trends in the prevalence of adolescent healthrelated behaviours. The future research should focus on a more detailed analysis of factors related to the recent decline, as well as to possibly different effects of preventative measures between adolescents coming from the distinctive social environment.

\section{CONCLUSIONS}

The findings of our study demonstrated the declining trend of tobacco consumption among the Czech adolescents. The trend is 
apparent among both boys and girls, and there are rather minor differences in this respect. However, given the higher prevalence of smoking among adolescent girls, as compared to boys in recent periods, there are some implications that should not be neglected.

As suggested by our findings, preventive programmes instituted in the Czech schools should pay more attention to genderspecific perceptions and norms related to smoking behaviour. Moreover, existing regulatory measures on the sale of tobacco products to minors need to be enforced vigorously as, unfortunately, there are some deficiencies $(17,25)$.

\section{Acknowledgements}

This paper was supported by the Czech Ministry of Education, Youth and Sport under contracts no. LG 14043, LG 14042 and under the NPU I programme no. LO1611 "Sustainability for the National Institute of Mental Health".

\section{Conflict of Interests}

None declared

\section{REFERENCES}

1. World Health Organization. WHO report on the global tobacco epidemic, 2011: warning about the dangers of tobacco. Geneva: World Health Organization; 2011.

2. Peto R, Lopez AD, Boreham J, Thun M, Heath C. Mortality from smoking in developed countries 1950-2000: indirect estimation from national vital statistics. New York: Oxford University Press; 1994.

3. Jha P, Ramasundarahettige C, Landsman V, Rostrom B, Thun M, Anderson $\mathrm{RN}$, et al. 21st century hazards of smoking and benefits of cessation in the United States. N Engl J Med. 2013 Jan 24;368(4):341-50.

4. GBD 2015 Tobacco Collaborators. Smoking prevalence and attributable disease burden in 195 countries and territories, 1990-2015: a systematic analysis from the Global Burden of Disease Study 2015. Lancet. 2017 May 13;389(10082):1885-906.

5. Eriksen M, Mackay J, Ross, H. The tobacco atlas. 5th ed. New York: American Cancer Society, World Lung Foundation; 2012.

6. Lamkin LP, Houston TP. Nicotine dependency and adolescents: preventing and treating. Prim Care. 1998 Mar;25(1):123-35.

7. Cosci F, Pistelli F, Lazzarini N, Carrozzi L. Nicotine dependence and psychological distress: outcomes and clinical implications in smoking cessation. Psychol Res Behav Manag. 2011;4:119-28.

8. Audrain-McGovern J, Rodriguez D, Rodgers K, Cuevas J, Sass J, Riley T. Reward expectations lead to smoking uptake among depressed adolescents. Drug Alcohol Depend. 2012 Jan 1;120(1-3):181-9.

9. Page RM, Zarco EPT, Ihasz F, Suwanteerangkul J, Uvacsek M, Mei-Lee $\mathrm{C}$, et al. Cigarette smoking and indicators of psychosocial distress in Southeast Asian and Central-Eastern European adolescents. J Drug Educ. 2008;38(4):307-28

10. Fry G, Grogan S, Gough B, Conner M. Smoking in the lived world: how young people make sense of the social role cigarettes play in their lives. Br J Soc Psychol. 2008 Dec;47(Pt 4):763-80.
11. Sovinová H, Csémy L, Provazníková H, Rážová J, Krch FD. Trends in cigarette smoking in Czech children and adolescents in the period of 1994 through 2002. Čes Slov Hyg. 2004;1(2):43-6. (In Czech.)

12. Csémy L, Sovinová H, Rážová J, Provazníková H. Trends in cigarette smoking in Czech children and adolescents form 1994 through 2006 and selected smoking associations among adolescents. Hygiena. 2008;53(2):48-52. (In Czech.)

13. Inchley J, Currie D, Young T, Samdal O, Torsheim T, Augustson L, et al., editors. Growing up unequal: gender and socioeconomic differences in young people's health and well-being. Health Behaviour in School-aged Children (HBSC) study: international report from the 2013/2014 survey. Copenhagen: WHO Regional Office for Europe; 2016.

14. Hublet A, De Bacquer D, Valimaa R, Godeau E, Schmid H, Rahav G, et al. Smoking trends among adolescents from 1990 to 2002 in ten European countries and Canada. BMC Public Health. 2006 Nov 10;6(1):280.

15. Baška T, Warren CW, Bašková M, Jones NR. Prevalence of youth cigarette smoking and selected social factors in 25 European countries: findings from the Global Youth Tobacco Survey. Int J Public Health. 2009;54(6):439-45.

16. Warren CW, Jones NR, Eriksen MP, Asma S; Global Tobacco Surveillance System (GTSS) collaborative group. Patterns of global tobacco use in young people and implications for future chronic disease burden in adults. Lancet. 2006 Mar 4;367(9512):749-53.

17. Greplová J. Prevalence of smoking and attitudes towards tobacco use among minors in the Czech Republic. Adiktologie. 2013;13(3-4):240-7. (In Czech.)

18. Kraus L, Guttormsson U, Leifman H, Arpa S, Molinaro S, Monshouwer K, et al. ESPAD Report 2015. Results from the European School Survey Project on Alcohol and Other Drugs. Luxembourg: Publications Office of the European Union; 2016.

19. Chomynová P, Csémy L, Grolmusová L, Sadílek P. The European School Survey Project on Alcohol and Other Drugs (ESPAD): results of survey in the Czech Republic in 2011. Prague: Office of the Government of the Czech Republic; 2014. (In Czech.)

20. Sovinová H, Csémy L. Smoking behaviour of Czech adolescents: results of the Global Youth Tobacco Survey in the Czech Republic, 2002. Cent Eur J Public Health. 2004 Mar;12(1):26-31.

21. Lopez AD, Collishaw NE, Piha T. A descriptive model of the cigarette epidemic in developed countries. Tob Control. 1994 Sep;3(3):242-7.

22. Waldron I. Patterns and causes of gender differences in smoking. Soc Sci Med. 1991;32(9):989-1005.

23. Patrick DL, Cheadle A, Thompson DC, Diehr P, Koepsell T, Kinne S. The validity of self-reported smoking: a review and meta-analysis. Am J Public Health. 1994 Jul;84(7):1086-93.

24. Newell SA, Girgis A, Sanson-Fisher RW, Savolainen NJ. The accuracy of self-reported health behaviors and risk factors relating to cancer and cardiovascular disease in the general population: a critical review. Am J Prev Med. 1999 Oct;17(3):211-29.

25. Hrubá D, Okrajek P, Kukla L. Factors influencing the experimentation with smoking: observed in ELSPAC Study. Čas Lék Čes. 2012;151(3):141-8.

Received March 9, 2017 Accepted in revised form July 13, 2017 